\title{
Implementación de métodos moleculares y microscópicos para estudios clínicos y ambientales relativos a Cryptosporidium sp. en Uruguay
}

\section{Implementation of Molecular and Microscopy Methods for Clinical and Environmental Studies on Cryptosporidium}

\author{
sp. in Uruguay
}

Rey, Fabiana (1), Acosta, Silvina (2), Martínez, Wilner (2), Lena, Anaydé (3), Tort, Cecilia (3), Acuña, Ana (3), Míguez, Diana (1), Ureta, Alejandro (4)

(1) Gerencia I+D+i, Laboratorio Tecnológico del Uruguay, LATU / Fundación LATITUD.

(2) Servicio de Biodosimetría. Instituto de Investigaciones Biológicas Clemente Estable, IIBCE. Ministerio de Educación y Cultura.

(3) Departamento de Parasitología y Micología, Instituto de Higiene, Facultad de Medicina, Universidad de la República, UdelaR.

(4) Gerencia de Agua Potable, Obras Sanitarias del Estado, OSE.

Contacto: correo.aureta@gmail.com

RECIBIDO: 15/8/2016 - APROBADO: 25/11/2016

\begin{abstract}
Resumen
El género Cryptosporidium se compone de protozoarios parásitos que infectan las células epiteliales del tracto gastrointestinal de una amplia variedad de vertebrados. Esta parasitosis puede ser adquirida por diferentes vías que incluyen el contacto directo con personas o animales infectados y la ingestión de alimentos o aguas contaminadas con el estadío ambiental de este microorganismo, el ooquiste. La significación sanitaria y ambiental de este parásito hace necesario para Uruguay implementar herramientas específicas, rápidas y robustas que permitan un estudio adecuado de su incidencia clínica y distribución ambiental (temporal y geográfica). En este trabajo se describe la implementación de métodos moleculares y de microscopía que contribuirán en su conjunto al conocimiento de la incidencia sanitaria y distribución ambiental de este protozoario, así como a mitigar el riesgo que Cryptosporidium sp. potencialmente representa en nuestro país.

Palabras clave: Cryptosporidium, ambiente, aguas, epidemiología.

Summary

The Cryptosporidium genus is composed of protozoan parasites that infect the epithelial cells of the gastrointestinal tract of a wide range of vertebrates. This parasitosis can be transmitted through routes that include the direct contact with infected animals or persons as well as through the ingestion of food or water containing the environmental stage of this microorganism, the oocysts. The sanitary and environmental significance of this parasite makes necessary for Uruguay to implement specific, fast and robust tools enabling a proper study of their clinical impact as well as its environmental distribution (temporal and geographical). This paper describes the implementation of molecular and microscopy methods that will contribute to the understanding of the clinical incidence and environmental distribution of these protozoa as well as to the mitigation of the risk that Cryptosporidium potentially represents in our country.

Keywords: Cryptosporidium, environment, water, epidemiology.
\end{abstract}

\section{Introducción}

El género Cryptosporidium se compone de protozoarios parásitos que infectan las células epiteliales del tracto gastrointestinal de una amplia variedad de vertebrados (Tyzzer, 1910; Slavin, 1955; Current y Garcia, 1991; O’Donoghue, 1995; de
Graaf, et al., 1999; O’Handley y Olson, 2006). A pesar de las similitudes con otros grupos de coccidios, Cryptosporidium demuestra varias particularidades, como su localización y colonización de la superficie apical de las células hospederas, 
constituyéndose en parásitos intracelulares pero extracitoplásmicos (Levine, 1984; Tzipori y Widmer, 2000; Petry, 2004). Esta parasitosis puede ser adquirida por diferentes vías que incluyen el contacto directo con personas o animales infectados y la ingestión de alimentos o aguas contaminadas con el estadío ambiental de este microorganismo, sus ooquistes (Bouzid, et al., 2013).

Cryptosporidium es un microorganismo significativo en la industria del agua debido fundamentalmente al gran número de ooquistes liberados al ambiente por animales parasitados, a la baja dosis infectiva que evidencian, a su persistencia en aguas ambientales y a la resistencia que muestran a las concentraciones de desinfectante y tiempos de contacto correspondientes normalmente empleados en el proceso de producción de agua potable (Miller, et al., 1990; DuPont, et al., 1995; Chappell, et al., 1996; Ives, et al., 2007; Castro-Hermida, et al., 2008; Shields, et al., 2008; Mons, et al., 2009; Chalmers, 2012; Bouzid, et al., 2013).

Actualmente se reconocen alrededor de 25 especies de Cryptosporidium sp. capaces de parasitar peces, anfibios, reptiles, aves y mamíferos (Chalmers, 2012). La comprensión de las dinámicas de transmisión y el riesgo sanitario representado por ellas ha sido lento y complejo, en gran medida debido a que las especies de este protozoario son indistinguibles entre sí por los métodos de microscopía óptica. Hoy, gracias al aporte de los métodos moleculares, es posible llevar adelante estudios profundos en relación a la epidemiología y origen ambiental de estos protozoarios (Plutzer y Karanis, 2009; Fayer, et al., 2010; Xiao, 2010; Ng, et al., 2011; Chalmers, 2012). En este sentido, herramientas basadas en el PCR han permitido, por medio de la detección e identificación de especies, familias y subtipos moleculares, evaluar el riesgo sanitario que ellas representan. Es así por ejemplo que pudo determinarse que Cryptosporidium hominis, seguido por Cryptosporidium parvum son las especies más comúnmente asociadas a la criptosporidiosis en humanos. Conjuntamente con las metodologías para identificar especies se han venido evaluando e implementando herramientas para el estudio y análisis de las relaciones intra-específicas que han permitido definir y asignar dentro de las especies de este protozoario, diversas familias y subtipos moleculares (Strong, et al., 2000; Sulaiman, et al., 2005; Cama, et al.; 2007; Tanriverdi, et al., 2007; Plutzer y Karanis, 2009; Dyachenko, et al., 2010; Fayer, et al., 2010; Xiao, 2010; Ng, et al., 2011; Chalmers, 2012). Estas herramientas, basadas en la amplificación por PCR y análisis de las secuencias nucleotídicas polimórficas, como por ejemplo la región ITS-2, minisatélites y microsatélites tradicionales o la región 3' del gen gp60 de este microorganismo, han sido y continúan siendo empleadas para el estudio de la transmisión de Cryptosporidium hominis en humanos y Cryptosporidium parvum en animales y humanos, así como para la evaluación del origen de eventos de contaminación ambiental por estos protozoarios (Strong, et al., 2000; Sulaiman, et al., 2005; Cohen, et al., 2006; Cama, et al., 2007; Tanriverdi, et al., 2007; Geurden, et al., 2009; Plutzer y Karanis, 2009; Xiao, et al., 2009; Dyachenko, et al., 2010; Fayer, et al., 2010; Xiao, 2010; Chalmers, et al., 2011; Ng, et al., 2011; Waldron, et al., 2011; Chalmers, 2012; Koehler, et al., 2013).

De las mencionadas anteriormente, la herramienta molecular de mayor uso en la identificación de familias y subtipos en especies de Cryptosporidium sp. es la secuencia del gen gp60, que codifica una glicoproteína de $60 \mathrm{KDa}$ localizada en la superficie apical de las formas invasivas de este protozoario y que en humanos es el blanco principal de la respuesta inmune humoral durante procesos infectivos (Gatei, et al., 2006; Leoni, et al., 2007; Leoni, et al., 2007; Wielinga, et al., 2008; Johnson, et al., 2013). Aun cuando se han descrito otros marcadores capaces de discriminar subtipos de este parásito, el nivel de polimorfismo de $g p 60$ (dado fundamentalmente por el número de tripletes o codones repetidos para el aminoácido Serina) y el rol biológico de la glicoproteína correspondiente permite relacionar las características de este protozoario a su rango de hospederos y a las manifestaciones clínicas asociadas a cada familia y subtipo molecular (O'Connor, et al., 2007).

Esta herramienta de tipificación ha permitido realizar evaluaciones epidemiológicas de esta parasitosis así como el estudio del origen y seguimiento de brotes de criptosporidiosis asociados a alimentos y aguas (Peng, et al., 2001, Harper, et al., 2002; Harrison, et al., 2002; Sopwith, et al., 2005; Cama, et al., 2007; Chalmers, 2008; Hunter, et al., 2008; Wielinga, et al., 2008; Ethelberg, et al., 2009; Feng, et al., 2009; Ng, et al., 2010; Robinson y Chalmers, 2010; Smith y Nichols, 2010; Widmer y Lee, 2010; Gormley, et al., 2011; Ruecker, et al., 2012; Caccio, et al., 2013). Hasta hoy, el brote de criptosporidiosis ocurrido en el año 1993 en la ciudad de Milwaukee, EE.UU., con un estimado de 400.000 personas afectadas y aproximadamente 150 muertos, es el caso más importante y difundido (Mac Kenzie, et al., 1994). No obstante ello, brotes de esta parasitosis asociados a aguas ambientales y potables continúan ocurriendo (Baldursson y Karanis, 2011; Hlavsa, et al., 2011; Chalmers, 2012).

En función de la significación que la presencia de ooquistes de Cryptosporidium sp. en aguas tiene desde el punto de vista sanitario y ambiental es necesario para nuestro país contar con herramientas que permitan evaluar de forma específica y rápida la presencia y concentración de ooquistes de Cryptosporidium sp. en aguas ambientales, identificando al mismo tiempo las especies dominantes presentes, la integridad de sus ooquistes e integrando herramientas de tipificación que permitan conocer el origen animal o humano de contaminación por este parásito, la incidencia clínica de especies y subtipos, su significación epidemiológica así como su distribución ambiental.

En este trabajo, y considerando la potencial vinculación entre los aspectos clínicos y ambientales de esta parasitosis, se describe la implementación de métodos moleculares y microscópicos para el análisis de muestras clínicas y aguas que permitirán en su conjunto conocer la distribución ambiental e incidencia clínica de este parásito en Uruguay así como eventualmente mitigar el riesgo sanitario y ambiental asociado a este protozoario.

\section{Materiales y Métodos}

\section{Ooquistes de Cryptosporidium parvum}

Ooquistes infectivos de Cryptosporidium parvum de origen bovino correspondientes al aislamiento Iowa y obtenidos a partir de la parasitosis experimental de terneros fueron comercialmente adquiridos de la compañía Waterborne Inc. (New Orleans, USA) y preservados de acuerdo a las indicaciones del proveedor. La concentración de la solución de ooquistes fue verificada por conteo en cámara de Neubauer. A partir de estas determinaciones se prepararon soluciones 
de $5 \times 10^{4}, 5 \times 10^{3}, 5 \times 10^{2}$ y $5 \times 10^{1}$ ooquistes para extracción de ADN para evaluar el límite de detección de los ensayos de PCR de tiempo final y el comportamiento del kit de PCR de tiempo real empleado en este trabajo.

\section{Diagnóstico parasitológico de criptosporidiosis}

El diagnóstico de criptosporidiosis intestinal fue confirmado mediante el Examen Coproparasitario (realizado a través de determinaciones coproparasitarias) con técnicas de enriquecimiento según el método de Ritchie. Brevemente, las muestras de materia fecal fueron homogeneizadas en una solución $0,85 \%$ de $\mathrm{NaCl}$, filtradas y centrifugadas a $900 \mathrm{Xg}$ durante 1 minuto. El material sedimentado fue resuspendido y fijado con formol, extrayendo las grasas por medio de la adición de éter sulfúrico o acetato de etilo. Las muestras fueron nuevamente centrifugadas durante 2 minutos y parte del material sedimentado fue transferido a láminas portaobjetos para su evaluación microscópica, previa tinción según el método Kinyoun o Ziehl-Neelsen modificado (Manser, et al., 2014).

\section{Extracción de ADN a partir de ooquistes comerciales y materia fecal humana correspondiente a casos clínicos de criptosporidiosis}

Se extrajo ADN a partir de $5 \times 10^{4}, 5 \times 10^{3}, 5 \times 10^{2}$ y $5 \times 10^{1}$ ooquistes de Cryptosporidium parvum resuspendidos en $0,5 \mathrm{~mL}$ de buffer $100 \mathrm{mM}$ Tris- $\mathrm{HCl} \mathrm{pH} 8,100 \mathrm{mM}$ EDTA. Para ello, los ooquistes fueron sometidos a ciclos de congelado - descongelado en baño de hielo seco-alcohol y estufa a $70^{\circ} \mathrm{C}$, respectivamente. Completadas estas etapas se agregó 1 volumen de buffer de lisis ( $100 \mathrm{mM}$ Tris- $\mathrm{HCl} \mathrm{pH} \mathrm{8,100} \mathrm{mM}$ EDTA, $100 \mathrm{mM}$ NaH2PO4, $2 \mathrm{M} \mathrm{NaCl}, 1 \% \mathrm{CTAB}$ precalentado a $70{ }^{\circ} \mathrm{C}$ ) incubando las muestras a $70{ }^{\circ} \mathrm{C}$ durante 45 minutos. Transcurrido ese período se agregó Proteinasa $\mathrm{K}$ a una concentración final de $100 \mu \mathrm{g} / \mathrm{mL}$ incubando las muestras a $70{ }^{\circ} \mathrm{C}$ durante otros 45 minutos. A partir de ahí y para la purificación de $\mathrm{ADN}$ las muestras fueron procesadas con el QiAmp DNA Mini Kit (QIAGEN) según las instrucciones del fabricante y eluyendo el ADN en un volumen final de $50 \mu \mathrm{L}$.

Para la extracción de ADN a partir de materia fecal humana, $0,5 \mathrm{~g}$ de muestras no fijadas fueron homogeneizadas en buffer $100 \mathrm{mM}$ Tris- $\mathrm{HCl}$ pH 8, 100 mM EDTA. Una vez completada la homogenización, y para la extracción y purificación del ADN las muestras fueron tratadas según lo indicado anteriormente, con la excepción de que para la primera incubación de 45 minutos a $70^{\circ} \mathrm{C}$ se adicionó al buffer de lisis, lisozima a una concentración final de $100 \mu \mathrm{g} / \mathrm{mL}$.

\section{Detección de Cryptosporidium sp. por PCR de tiempo final y evaluación de especie por PCR-RFLP}

Las reacciones de PCR de tiempo final fueron llevadas adelante en equipos Palm Cycler (Corbett) modelo CG1-96. Las mezclas de PCR contuvieron $1 \mu \mathrm{L}$ de las soluciones correspondientes de $\mathrm{ADN}$ blanco, $50 \mu \mathrm{M}$ de cada deoxynucleósido trifosfato, $50 \mu \mathrm{g} / \mathrm{mL}$ de Albúmina Sérica Bovina, $1 \%$ de Dimetilsulfóxido (DMSO), $2 \mathrm{mM}$ de $\mathrm{mgCl}_{2}, 20$ pmoles de primers directo y reverso y 1.5 Unidades de ADN polimerasa Taq en un volumen final de $25 \mu \mathrm{L}$ en una solución $1 \mathrm{X}$ del buffer correspondiente. Para estas reacciones se utilizó un sistema de PCR anidado empleando los primers BcowpF (5'-ACC GCT TCT CAA CAA CCA TCT TGT CCT C-3') y BcowpR (5'-CGC ACC TGT TCC CAC TCA ATG TAA ACC C-3') para los primeros rounds y los primers Cry-15 (5'-GTA GAT AAT GGA AGA GAT TGT G-3'), y Cry-9 (5'-GGA CTG AAA TAC AGG CAT TAT CTT G-3') para los segundos rounds, los cuales permiten la amplificación de un fragmento del gen de copia única cowP1 (Xiao, et al., 2000). En este punto es importante destacar que dado que cada ooquiste de Cryptosporidium sp. contiene en su interior 4 esporozoítos haploides, cada ooquiste posee 4 copias del gen cowP1 (Bouzid, et al., 2013).

El perfil térmico de los primeros y segundos rounds consistió en una incubación inicial a $95^{\circ} \mathrm{C}$ durante 5 minutos, 35 ciclos de $94^{\circ} \mathrm{C}$ durante 1 minuto, $55^{\circ} \mathrm{C}$ durante 1 minuto y $72^{\circ} \mathrm{C}$ durante 1 minuto, seguidos por una extensión final a $72{ }^{\circ} \mathrm{C}$ durante 10 minutos con el posterior mantenimiento de las reacciones a $4{ }^{\circ} \mathrm{C}$.

Para la determinación de especies de Cryptosporidium dominantes, los productos de PCR fueron digeridos a $37^{\circ} \mathrm{C}$ con 10 Unidades de la enzima de restricción RsaI. Los productos de PCR y PCR-RFLP fueron resueltos por electroforesis en agarosa al 2\% y teñidos con el compuesto Gel-Red. Los marcadores de peso molecular empleados fueron los marcadores M0623 o M1331 (Fermentas), de acuerdo a lo indicado en las Figuras 1, 2, 3 y 5.

\section{Amplificación del gen $g p 60$, secuenciación y evaluación de familias y subtipos de Cryptosporidium hominis}

Para la determinación de las familias y subtipos clínicos de Cryptosporidium hominis identificados en este trabajo se empleó un sistema de PCR anidado para la amplificación y análisis de la secuencia nucleotídica de un fragmento del gen gp60 de este protozoario. Las mezclas de PCR contuvieron $1 \mu \mathrm{L}$ de las soluciones correspondientes de ADN blanco, $50 \mu \mathrm{M}$ de cada deoxynucleósido trifosfato, $1 \mu \mathrm{g}$ de Albúmina Sérica Bovina, $1 \%$ de Dimetilsulfóxido (DMSO), $1 \mathrm{mM}$ de $\mathrm{mgCl}_{2}$, 20 pmoles de primers directo y reverso y 1.5 Unidades de ADN polimerasa Taq en un volumen final de $25 \mu \mathrm{L}$ en una solución 1X del buffer correspondiente. Los primers AL3531 (5'-ATAGTCTCCGCTGTATTC-3') y AL3535 (5'-GAGATATATCTTGGTGCG-3') fueron empleados para los primeros rounds de estas amplificaciones, mientras que los primers AL3532 (5'-TCCGCTGTATTCTCAGCC-3') y AL3534 (5'-GAACCACATTACAAATGAAG-3') fueron empleados para los segundos rounds de PCR (Alves, et al., 2003). El perfil térmico tanto de los primeros y segundos rounds consistió en una incubación inicial a $95^{\circ} \mathrm{C}$ durante 5 minutos, 35 ciclos de $94^{\circ} \mathrm{C}$ durante 1 minuto, $55^{\circ} \mathrm{C}$ durante 1 minuto y $72^{\circ} \mathrm{C}$ durante 1 minuto, seguidos por una extensión final a $72^{\circ} \mathrm{C}$ durante 10 minutos con el posterior mantenimiento de las reacciones a $4{ }^{\circ} \mathrm{C}$. Los productos de PCR fueron resueltos por electroforesis en agarosa al $2 \%$ y teñidos con el compuesto Gel-Red.

Los productos de PCR obtenidos fueron secuenciados en ambas direcciones por el método de Sanger por la compañía Macrogen, Inc. (Korea). Las secuencias de ADN obtenidas fueron almacenadas y analizadas en el software MEGA 7 
(v 7.0.18) tomando como referencia las secuencias Genbank AF164502 (familia Ia), AY262031 (familia Ib), DQ665692 (familia Id), AY738184 (familia Ie), AF440638 (familia If), EF208067 (familia Ig), FJ971716 (familia Ih), HM234173 (familia Ii) y JF681174 (familia Ij). La pertenencia a las familias y subtipos fueron respectivamente evaluadas a través del alineamiento empleando el algoritmo Clustal W del análisis de la relación filogenética realizada, según el método Neighbor-Joining (NJ), y por la evaluación del tipo y número de microsatélites presentes en las mismas, según lo establecido al respecto (Alves, et al., 2003; Sulaiman, et al., 2005).

\section{Evaluación de la presencia de Cryptosporidium sp. en aguas ambientales}

Muestras de $100 \mathrm{~mL}$ de agua correspondiente a un curso superficial fueron refrigeradas y transportadas al laboratorio para su inmediato procesamiento. Las muestras fueron filtradas en membranas compuestas de ésteres de celulosa con una porosidad de $1,2 \mu \mathrm{M}$ y de un diámetro de $47 \mathrm{mM}$ (Millipore). Completada la etapa de filtración, las membranas fueron transferidas a tubos tipo Falcon de $50 \mathrm{~mL}$ conteniendo $2 \mathrm{~mL}$ de buffer de lisis precalentado a $70^{\circ} \mathrm{C}$, resuspendiendo el material retenido por vortex y pipeteo. El ADN correspondiente fue extraído y purificado de acuerdo a lo indicado anteriormente.

\section{Cuantificación de Cryptosporidium $s p$. por PCR de tiempo real}

Las reacciones de PCR de tiempo real fueron llevadas adelante en un equipo Rotorgene ${ }^{\mathrm{Tx}}$ modelo R6 6000 (Corbett). Para estos ensayos se emplearon los kits Genesig ${ }^{\oplus}$ Cryptosporidium Oocyst Wall Protein (COWP) gene Kit (PrimerDesign Ltd) y Oasig ${ }^{\text {Tm }}$ qPCR Mastermix (PrimerDesign Ltd). Al igual que el sistema de PCR de tiempo final implementado, este sistema de PCR basa la cuantificación en la amplificación de un fragmento del gen cowP1 de este protozoario. Se verificó el comportamiento de estos kits a partir de ensayos de cuantificación del material standard incluido (copias génicas de cowP1) y la respuesta de amplificación a 250 ooquistes (1000 copias génicas) de acuerdo a lo evaluado en los conteos en cámara de Neubauer. Las mezclas de reacción (conteniendo $1 \mu \mathrm{L}$ de cada solución de ADN) y perfiles térmicos fueron los indicados por el fabricante.

\section{Siembra de ooquistes de Cryptosporidium parvum en agua distribuida, recuperación y extracción de ADN}

Se emplearon 3 diluciones seriadas al medio ooquistes comerciales de Cryptosporidium parvum para la adición a $20 \mathrm{~L}$ de agua de distribución a ser filtrada por vacío en membranas compuestas de ésteres de celulosa con una porosidad de $1,2 \mu \mathrm{M}$ y de un diámetro de $47 \mathrm{mM}$ (Millipore). Completada la filtración, las membranas fueron transferidas a tubos tipo Falcon de $50 \mathrm{~mL}$ con $2 \mathrm{~mL}$ de buffer de lisis y resuspendiendo los ooquistes por vortex y pipeteo. Una vez eluídos, el ADN correspondiente fue extraído y purificado de acuerdo a lo indicado anteriormente para llevar adelante reacciones de PCR de tiempo real.

\section{Identificación y recuento de ooquistes de Cryptosporidium parvum mediante ensayos de inmunomarcación y microscopía de fluorescencia}

Para la identificación y recuento de ooquistes de Cryptosporidium parvum fue empleado el kit A400FLK Crypt-a-Glo ${ }^{\mathrm{Tx}}$ Comprehensive Kit de la compañía Waterborne Inc. (New Orleans, USA) de acuerdo a las instrucciones del fabricante. Entre otros, este sistema está compuesto por un anticuerpo monoclonal (desarrollado en ratón) contra epítopes exteriores de los ooquistes de Cryptosporidium sp. conjugado al fluorocromo Fluorescein-isothiocianato (FITC) y por el compuesto Evan's Blue (EB).

Para la fijación de los ooquistes sobre portaobjetos, se colocaron $20 \mu \mathrm{L}$ de muestra en Cytospin que se centrifugaron en un equipo Cellspin ${ }^{\oplus}$ (Tharmac) a 2000 rpm durante $10 \mathrm{~min}$. Para las evaluaciones por microscopía de inmunofluorescencia se emplearon los equipos Axioplan I con contraste de fase y Axioplan Mot II acoplado a un sistema de imágenes automatizado denominado ISIS (MetaSystems GmbH, Germany). Las muestras analizadas correspondieron a los ooquistes de la solución comercial adquirida así como también a ooquistes de Cryptosporidium parvum sembrados en agua ambiental, retenidos y recuperados a partir de la filtración en membrana de acuerdo a lo indicado anteriormente.

\section{Resultados}

Evaluación del sistema de PCR y PCR-RFLP para la detección y determinación de especie de Cryptosporidium sp.

Los resultados de la amplificación por PCR anidado del gen cowP1 de Cryptosporidium sp. y la determinación de especie por PCR-RFLP se presentan en la Figura 1. Para estos ensayos se extrajo ADN a partir de $5 \times 10^{4}, 5 \times 10^{3}, 5 \mathrm{X} 10^{2} \mathrm{y}$ $5 \mathrm{X} 10^{1}$ ooquistes comerciales de Cryptosporidium parvum realizando reacciones de PCR a partir de volúmenes de muestras de $\mathrm{ADN}$ equivalentes a $10^{3}, 10^{2}, 10^{1}$ y $10^{0}$ ooquistes. Los resultados obtenidos muestran que si bien el primer round de PCR (producto de amplificación de 769 pb) evidencia un límite de detección equivalente a entre 100 y 10 ooquistes (correspondiente a 400 y 40 copias génicas, respectivamente), el segundo round correspondiente al PCR anidado (producto de amplificación de 550 pb) evidencia un límite de detección equivalente a alrededor de 1 ooquiste (correspondiente a 4 copias génicas). Estos ensayos fueron repetidos al menos 5 veces, evidenciando en lo que respecta a este parámetro una mayor sensibilidad a lo reportado por Yu y colaboradores (Yu, et al., 2009) para este sistema de PCR.

La incorporación de etapas de congelado - descongelado para la extracción de $\mathrm{ADN}$ hecha en este trabajo explica la mayor sensibilidad alcanzada.

La repetitividad de los perfiles de restricción obtenidos con la enzima RsaI a partir de los segundos rounds de amplificación (primers Cry-15 y Cry-9), de acuerdo a lo indicado en la Figura 1, generados a partir de distintas cantidades iniciales de copias génicas, evidencia el buen funcionamiento de las condiciones de restricción para la identificación de especies 


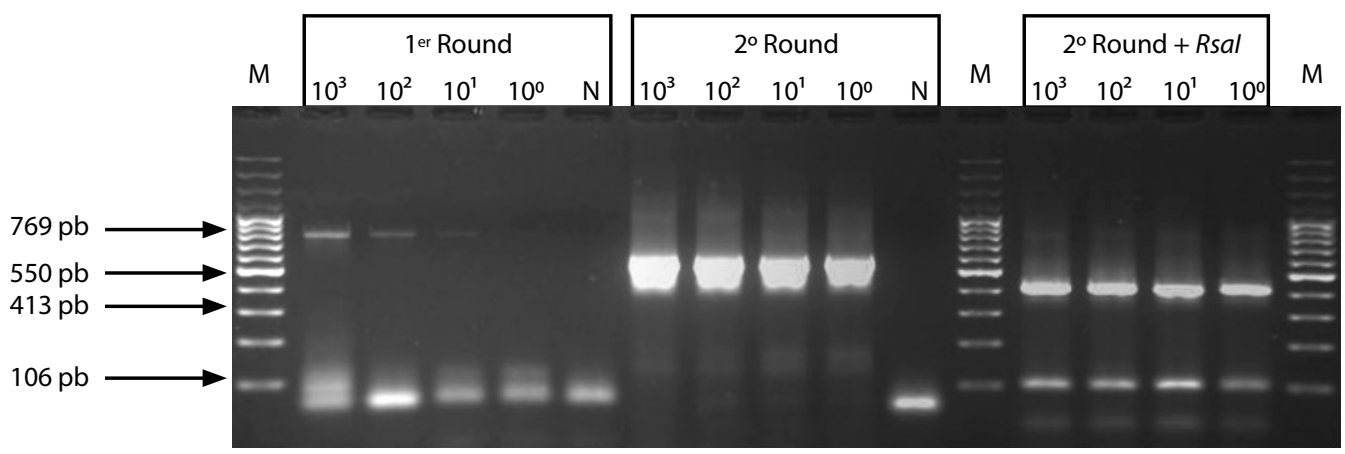

Figura 1. Evaluación del comportamiento del sistema de PCR y PCR-RFLP en la detección y determinación de especie de Cryptosporidium sp. Se indican los límites de detección del primer (1 1 er Round) y segundo round ( $2^{\circ}$ Round) del sistema de amplificación del gen cowP1 de este protozoario así como el perfil de restricción obtenido con la enzima RsaI a partir de la restricción del producto amplificado en el segundo round de PCR del fragmento correspondiente a Cryptosporidium parvum comercial. $10^{3}, 10^{2}, 10^{1}, 10^{\circ}$ indica el equivalente en ooquistes al ADN presente en cada reacción. N: Control Negativo. M: Marcador de peso molecular M0623 (Fermentas). Las flechas indican el tamaño de los amplicones y productos de restricción correspondiente. La figura representa una de 10 réplicas en lo que respecta a los límites de detección del sistema implementado.

\begin{tabular}{|c|c|c|c|c|c|}
\hline Matrices & $\begin{array}{c}\text { Positivos previo a la } \\
\text { siembra de ooquistes }\end{array}$ & $\begin{array}{c}\text { Falsos } \\
\text { negativos }\end{array}$ & $\begin{array}{c}\text { Límite de detección } \\
\text { (equivalente a ooquistes) }\end{array}$ & Repetitividad & RFLP \\
\hline Agua MilliQ * & $0(5)$ & $0(5)$ & 1 & $5(5)$ & $\mathrm{Si}$ \\
Agua potable distribuída * $^{\text {Agua superficial * }}$ & $0(5)$ & $0(5)$ & 1 & $5(5)$ & $\mathrm{Si}$ \\
Afluente residual doméstico & $0(5)$ & $0(5)$ & 1 & $5(5)$ & $\mathrm{Si}$ \\
Materia fecal humana \& & $0(5)$ & $0(5)$ & 1 & $\mathrm{Si}$ & $\mathrm{Si}$ \\
Materia fecal bovina * & $0(5)$ & $0(5)$ & 1 & $5(5)$ & $\mathrm{Si}$ \\
\hline
\end{tabular}

* Ooquistes comerciales sembrados

\& casos clínicos de criptosporidiosis

Tabla 1. Performance de los sistemas de PCR de tiempo final anidado y PCR-RFLP para la detección del gen cowP1 de Cryptosporidium sp. Previo a las siembras de ooquistes en las matrices analizadas las reacciones de PCR anidado no detectaron la presencia del protozoario. Una vez sembradas no se observaron falsos negativos.

de Cryptosporidium sp. empleadas en este trabajo de acuerdo al sistema de PCR-RFLP inicialmente descrito por Xiao y colaboradores (Xiao, et al., 2000). La performance del sistema de PCR de tiempo final y PCR-RFLP implementado se resumen en la Tabla 1.

Su especificidad y robustez fue también evaluada a partir del análisis de casos clínicos de criptosporidiosis en humanos. Tal como se evidencia en la Figura 2, el sistema de PCR implementado permitió confirmar en estos pacientes el diagnóstico clínico correspondiente y determinar la especie responsable de dichas parasitosis. En este sentido y de acuerdo a los perfiles de restricción obtenidos (productos de restricción para el segundo round de PCR de 284, 129 y 106 pb en cada caso), la especie presente en ambos pacientes corresponde a Cryptosporidium hominis. Análisis de metagenómica correspondientes a estas muestras clínicas (datos no presentados) mostraron además la especificidad del sistema de PCR implementado considerando que dichas reacciones tuvieron lugar en un background en los que el ADN de un amplio grupo de microorganismos evidencia amplificabilidad.

\section{Determinación de familia y subtipos de Cryptosporidium sp.}

Con el objetivo de implementar herramientas que permitan evaluar la epidemiología de esta parasitosis y el origen de potenciales eventos de contaminación ambiental por este protozoario, se implementó un sistema de PCR que permite a través de la amplificación y análisis de la secuencia nucleotídica de un fragmento del gen $g p 60$ determinar la familia y el subtipo de dicho microorganismo (Alves, et al., 2003; Sulaiman, et al., 2005; Cama, et al., 2007). Estas determinaciones fueron realizadas a partir de los casos clínicos humanos evaluados y que corresponden a infecciones por Cryptosporidium hominis, de acuerdo a lo expresado anteriormente. En este sentido, mientras que la Figura 3 evidencia el buen desempeño del sistema de PCR anidado implementado, la Figura 4 refleja la familia taxonómica a la que el análisis de las secuencias de dichos amplicones permitió asignar (Familia Id). Estos análisis permitieron además asignar al subtipo IdA19T4 a las especies de Cryptosporidium hominis asociadas a dichas parasitosis. La significación de este hallazgo será evaluada en la medida que un mayor número de casos clínicos sean analizados. 


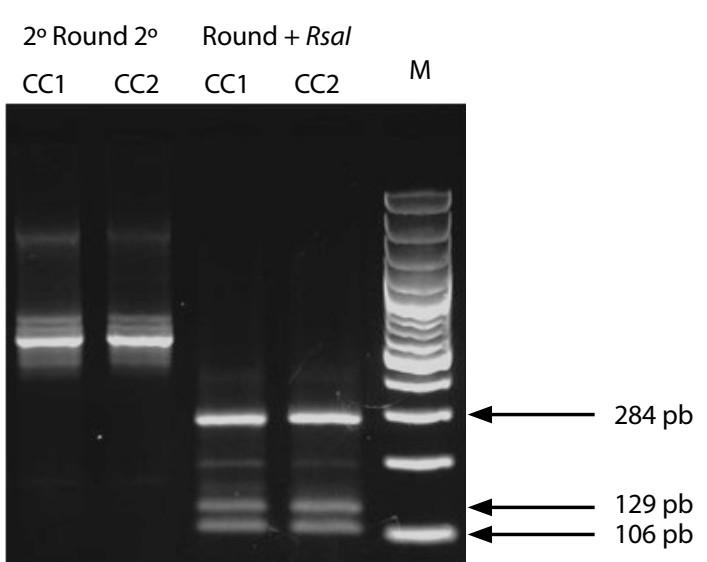

Figura 2. Determinación por PCR-RFLP de la especie de Cryptosporidium (Cryptosporidium hominis) presente en la materia fecal de dos casos clínicos de criptosporidiosis. La figura muestra los resultados del segundo round $\left(2^{\circ}\right.$ Round) de amplificación del gen cowP1 empleando ADN total extraído de las muestras clínicas evaluadas así como los resultados de las restricciones correspondientes con la enzima RsaI ( $2^{\circ}$ Round + RsaI). CC1: Caso Clínico 1, CC2: Caso Clínico 2. M: Marcador de peso molecular M1331 (Fermentas). Las flechas indican el tamaño de los productos de PCR y fragmentos de restricción correspondiente. La figura representa una de 3 réplicas en lo que respecta a las amplificaciones por PCR y restricciones correspondientes.

\section{Evaluación de la presencia de Cryptosporidium sp. en aguas ambientales}

Como primer paso para evaluar con estas metodologías la potencial presencia y especie dominante de Cryptosporidium sp. en aguas ambientales del Uruguay, se realizaron ensayos de PCR de tiempo final y PCR-RFLP a partir del ADN total extraído de $100 \mathrm{~mL}$ de muestras extraídas de un curso de agua superficial próximo a una zona industrializada. Los resultados mostrados en la Figura 5, representativos de dos campañas de muestreo realizadas con 15 días de separación, permiten concluir la presencia de Cryptosporidium parvum. La evaluación de si estos resultados obedecieron a un único evento de contaminación, así como su origen (animal o humano) y las potenciales fuentes de contaminación deberán ser estudiados en detalle a través del seguimiento temporal y geográfico del cuerpo de agua correspondiente. Es importante notar que los muestreos indicados anteriormente fueron llevados a cabo durante un período de lluvias.

\section{Recuperación, cuantificación y evaluación de la integridad de ooquistes de Cryptosporidium sp.}

Para verificar el funcionamiento de los kits Genesig Cryptosporidium Oocyst Wall Protein (COWP) gene Kit (PrimerDesign Ltd) y Oasig qPCR Mastermix (Primer-

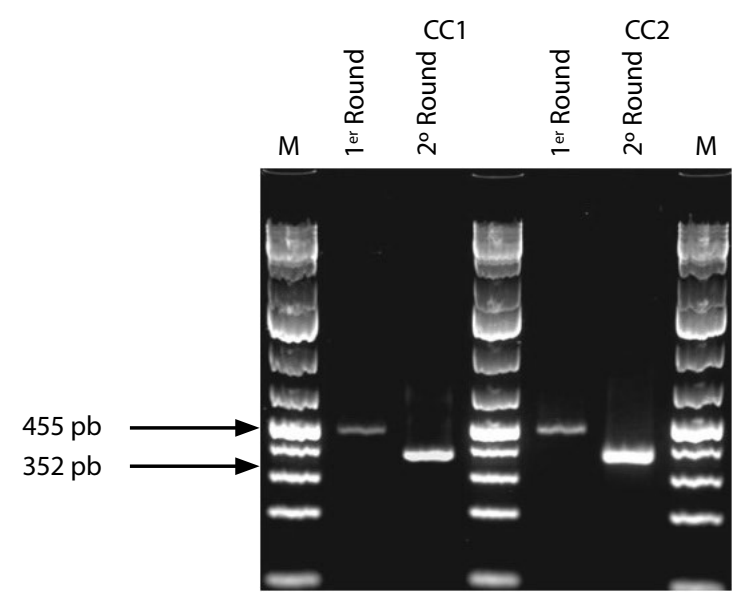

Figura 3. Amplificación por PCR de la región 3 correspondiente al gen gp60 de Cryptosporidium hominis identificados en los casos clínicos analizados en este trabajo. La figura muestra los resultados correspondientes a los primeros ( $1^{\text {er }}$ Round) y segundos rounds ( $2^{\circ}$ Round) de amplificación de dicha región génica. $\mathrm{CC} 1$ : Caso Clínico 1, CC2: Caso Clínico 2. M: Marcador de peso molecular M1331 (Fermentas). Las flechas indican el tamaño de los amplicones correspondientes. La figura representa una de 3 réplicas para ambos rounds de PCR.

Design Ltd) empleados para las reacciones de PCR de tiempo real, se llevaron adelante amplificaciones partiendo de diferentes números de copias génicas del gen $\operatorname{cow} P 1$ (material correspondiente al standard del kit empleado en este trabajo). La verificación de la performance del sistema de PCR de tiempo real empleado se resume en la Tabla 2. Asimismo, se incluyó en estos ensayos la evaluación del comportamiento de este sistema de PCR en la cuantificación de una cantidad inicial conocida de ooquistes (equivalente a 1000 copias génicas) comerciales de Cryptosporidium parvum. Un resultado representativo de estos análisis se presenta en la Figura 6 y muestra la linearidad del sistema para el rango del número de copias evaluadas. Cabe destacar que el número de copias génicas estimado por el equipo fue de alrededor de 800 , diferente de las 1000 copias génicas esperadas de acuerdo a lo agregado en las reacciones de PCR correspondientes. Esta diferencia es atribuible al error del método de conteo empleado (cámara de Neubauer) en la determinación del número de ooquistes inicialmente ensayados.

El procesamiento de muestras ambientales en las que evaluar la presencia de Cryptosporidium sp. requiere de una primera etapa de concentración de los ooquistes potencialmente presentes en ellas. La estrategia seguida en este trabajo para la recuperación o concentración de ooquistes fue de filtración en membranas (Xiao, et al., 2000; Xiao, et al., 2000; DiGiorgio, et al., 2002; Ferguson, et al., 2004; Lee, et al., 2004; Wohlsen, et al., 2004). Para evaluar la robustez de este método, diluciones seriadas al medio de ooquistes comerciales de este protozoario fueron sembrados en $20 \mathrm{~L}$ de agua distribuida. Luego de la filtración, 


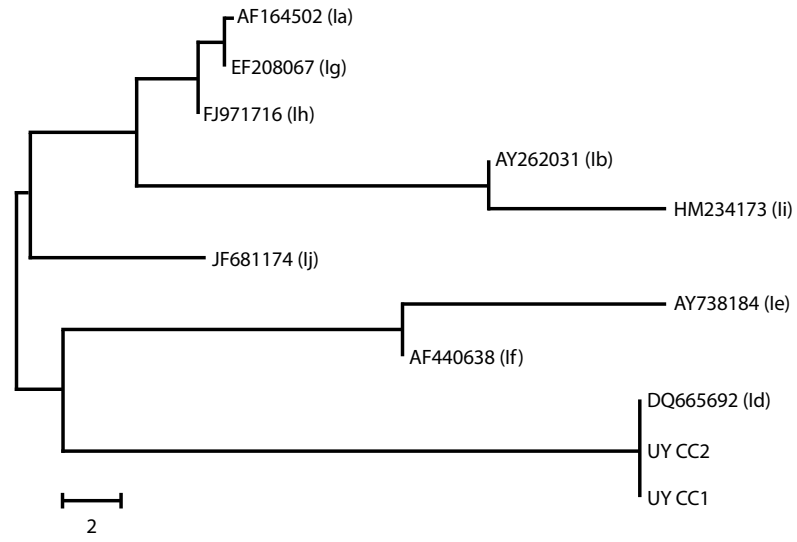

Figura 4. Relación taxonómica de familias del gen $g p 60$ de las especies de Cryptosporidium hominis identificados en los casos clínicos analizados en este trabajo y aislamientos de referencia. La proximidad taxonómica entre los casos clínicos analizados y el locus DQ665692 correspondiente a la familia Id del aislamiento 4308 de Cryptosporidium hominis, ubica a los casos clínicos analizados como pertenecientes a dicha familia. UY CC1: Caso Clínico 1, UY CC2: Caso Clínico 2.

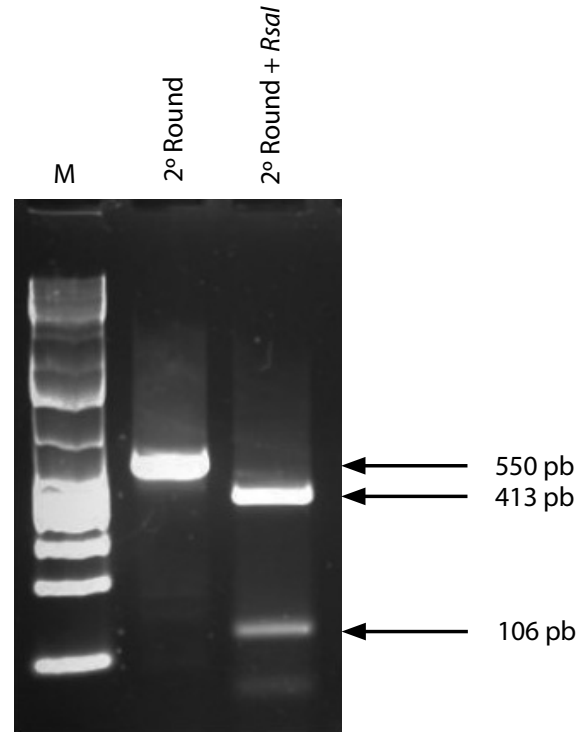

Figura 5. Detección de Cryptosporidium parvum en agua ambiental. La figura muestra los resultados del segundo round $\left(2^{\circ}\right.$ Round) de amplificación del gen cowP1 empleando ADN total extraído a partir de $100 \mathrm{~mL}$ de muestra correspondiente a un curso de agua superficial de Uruguay, así como los resultados de la restricción correspondiente con la enzima $R s a I\left(2^{\circ}\right.$ Round + RsaI). M: Marcador de peso molecular M1331 (Fermentas). Las flechas indican el tamaño de los amplicones y productos de restricción correspondiente. La figura representa una de 2 réplicas en lo que respecta a las amplificaciones por PCR y restricciones correspondientes.

\begin{tabular}{|c|c|c|c|c|}
\hline Matrices & $\begin{array}{c}\text { Verificación del } \\
\text { límite de cuantificación } \\
\text { (en copias génicas) }\end{array}$ & $\begin{array}{c}\text { Verificación } \\
\text { del rango dinámico } \\
\text { (en copias génicas) }\end{array}$ & Eficiencia & Valor predictivo $\left(\mathbf{R}^{2}\right)$ \\
\hline Agua MilliQ $^{*}$ & 100 & $100-10^{6}$ & $0.99-1$ & $0.99-1$ \\
\hline Agua potable distribuída * & 100 & $100-10^{6}$ & $0.99-1$ & $0.99-1$ \\
\hline
\end{tabular}

* Copias Génicas Estándar Sembradas

Tabla 2. Verificación de la performance del sistema de PCR de tiempo real empleado para la cuantificación del gen cowP1 de Cryptosporidium sp. Previo a las siembras de las copias génicas estándar las reacciones de PCR de tiempo real no detectaron la presencia del protozoario.

el material retenido fue eluído y el ADN correspondiente extraído y sometido a reacciones de PCR de tiempo real. Los resultados obtenidos mostraron una tendencia lineal con un $\mathrm{R}^{2}$ de 0,99 en la recuperación de ooquistes correspondientes a las diluciones seriadas evaluadas (Figura 7), lo que evidencia la robustez del método de recuperación. Para evaluar la significación sanitaria de la presencia ambiental de Cryptosporidium sp. no solo es fundamental determinar su concentración en las matrices analizadas y conocer la especie dominante presente sino también el grado de integridad de sus ooquistes. Para responder a esta interrogante en este trabajo se implementó un protocolo basado en microscopía de fluorescencia para la detección de ooquistes de este protozoario. El sistema implementado permite detectar de forma clara y específica ooquistes de Cryptosporidium parvum, ya sea presentes en solución comercial (Figura 8) o sembrados en aguas superficiales y recuperados por filtración en membrana (Figura 9). Es interesante apreciar en la Figura 8 ooquistes con su envoltura comprometida doblemente teñidos por EB y FITC (UK Environment Agency, 2010).

\section{Discusión}

Las parasitosis por Cryptosporidium sp. se encuentran ampliamente distribuidas a nivel mundial, no obstante se presume que la prevalencia es mayor en países no desarrollados 


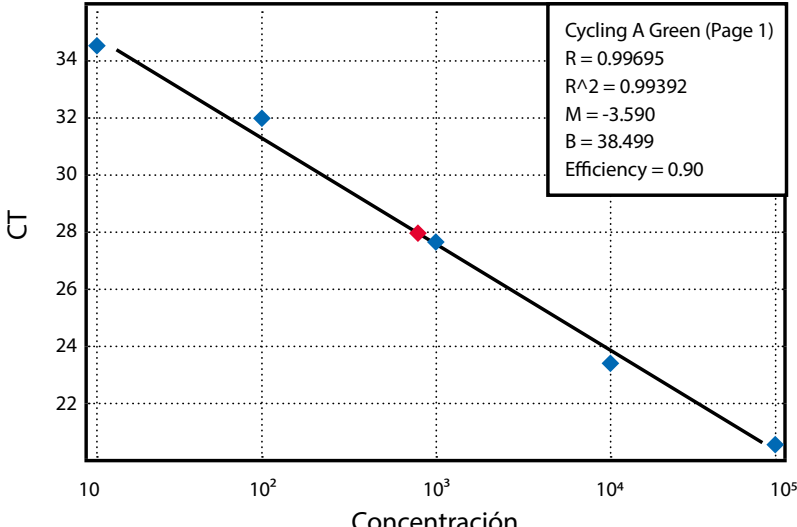

Figura 6. Evaluación (verificación) del comportamiento del sistema de PCR de tiempo real empleado en este trabajo. En azul se indican los CT correspondientes a $10^{5}, 10^{4}, 10^{3}, 10^{2}$ y $10^{1}$ copias génicas del standard del kit Genesig Cryptosporidium Oocyst Wall Protein (COWP) gene Kit (PrimerDesign Ltd) y Oasig qPCR Mastermix (PrimerDesign Ltd). En rojo se indica el CT correspondiente a la amplificación de 800 copias génicas iniciales de una preparación de ooquistes comerciales de Cryptosporidium parvum. El $\mathrm{R}^{2}$ de los resultados se indica en la parte superior derecha de la figura y es de 0.99392. La figura representa una de 3 réplicas en lo que respecta a las evaluaciones del sistema.

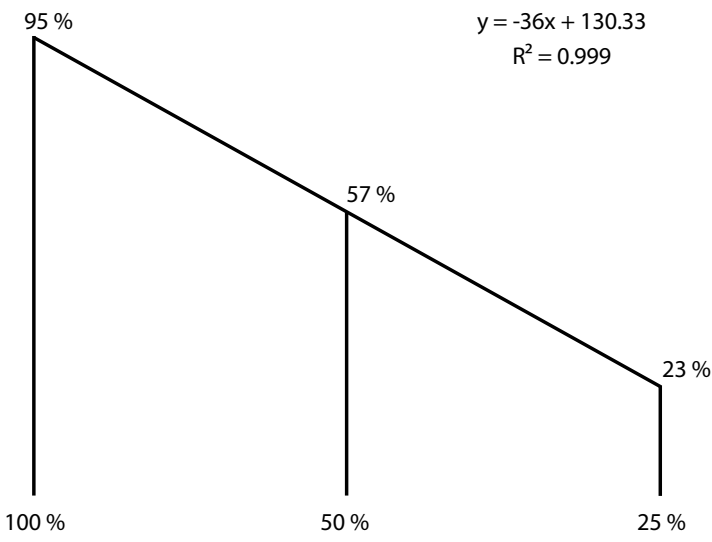

Figura 7. Evaluación por PCR de tiempo real de la robustez del sistema de recuperación de ooquistes de Cryptosporidium parvum de origen comercial por filtrado, retención y elución de membranas filtrantes. La figura muestra la tendencia lineal de la recuperación relativa de tres diluciones de ooquistes seriadas al medio. De los porcentajes esperados inicialmente (indicados en la base del gráfico) se indican sobre la curva del gráfico los porcentajes de recuperación obtenidos. Dichos porcentajes corresponden al promedio de 3 ensayos de siembra. El $\mathrm{R}^{2}$ de la curva obtenida se indica en la parte media superior del gráfico y es de 0.999 .
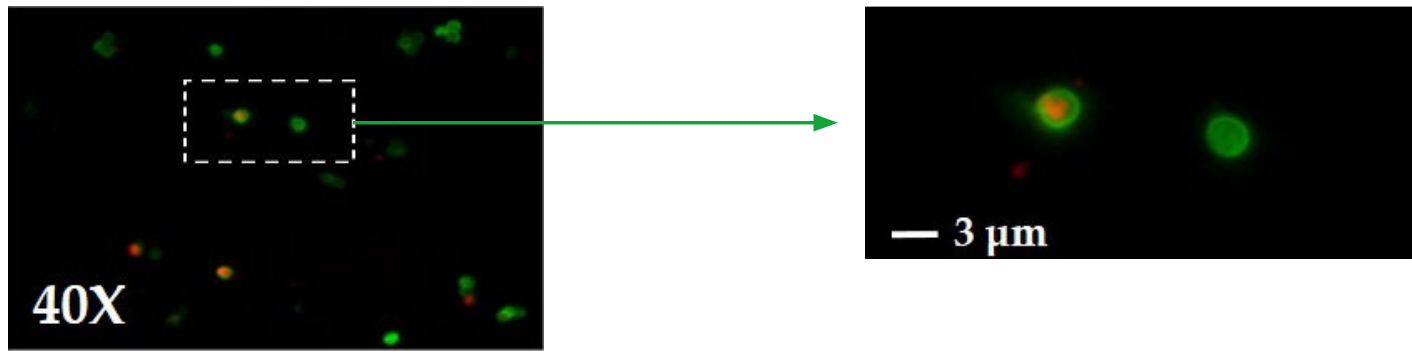

Figura 8. Inmunomarcación y detección por microscopía de fluorescencia de ooquistes comerciales de Cryptosporidium parvum. La imagen de la izquierda corresponde a una superposición de imágenes de los canales para los fluorocromos Evan's Blue (EB) y Fluorescein-isothiocianato (FITC) de uno de los campos fotografiados a 40 aumentos. La imagen de la derecha representa una magnificación digital de la zona delimitada por el rectángulo de líneas discontinuas en la imagen izquierda. En verde se aprecian los ooquistes de Cryptosporidium parvum, que también evidencian tinción por Evan’s Blue.

y afecta en humanos principalmente a la población infantil (Snelling, et al., 2007; Putignani y Menichella, 2010; Xiao, 2010). Entre los factores de riesgo asociados a estas parasitosis se encuentran los socioeconómicos y ambientales (por ejemplo, el acceso a un agua para consumo "segura" desde el punto de vista microbiológico), inmunocompetencia, estado de nutrición, edad, grado de contacto con animales y grado de hacinamiento o concentración de población (Robertson, et al., 2002; Goh, et al., 2004; Hunter, et al., 2004; Roy, et al., 2004; Lake, et al., 2007, Putignani y Menichella, 2010).

Es evidente la potencial contaminación de aguas ambientales, incluso aquellas empleadas como fuentes de agua potable, por parte de patógenos humanos y/o animales, incluyendo Cryptosporidium sp.. Esta contaminación puede asociarse al contacto directo de animales con cuerpos de agua, a la escorrentía de suelos contaminados y a potenciales fallas de los sistemas de tratamiento y/o disposición de aguas residuales, ya sean de origen humano o animal. La potencial diseminación ambiental de este protozoario, la intrínseca alta resistencia de sus ooquistes a las condiciones de desinfección normalmente empleadas durante el tratamiento de producción de agua potable, así como su capacidad para establecerse y sobrevivir en biofilms determinan que su presencia en aguas ambientales sea, al mismo tiempo, de especial significación para las empresas responsables de producir y distribuir este producto (Howe, et al., 2002; Angles, 

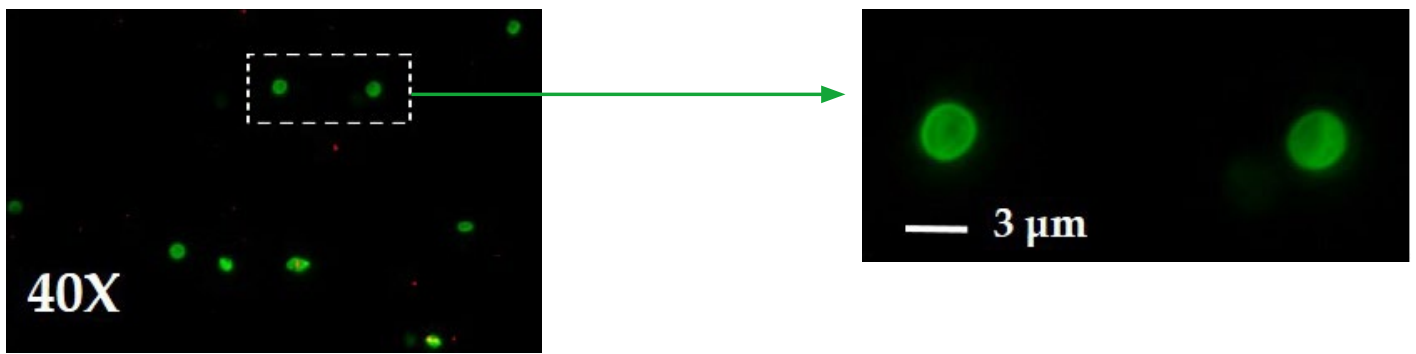

Figura 9. Inmunomarcación y detección por microscopía de fluorescencia de ooquistes comerciales de Cryptosporidium parvum sembrados en agua superficial (ambiental), recuperados por filtración y elución de membranas filtrantes. La imagen de la izquierda corresponde a una superposición de imágenes de los canales para los fluorocromos Evan's Blue (EB) y Fluorescein-isothiocianato (FITC) de uno de los campos fotografiados a 40 aumentos. La imagen de la derecha representa una magnificación digital de la zona delimitada por el rectángulo de líneas discontinuas en la imagen izquierda. En verde se aprecian los ooquistes de Cryptosporidium parvum. Si bien en esta figura se observa algo de material teñido por el colorante $\mathrm{EB}$, no se observan ooquistes doblemente teñidos por EB y FITC.

et al., 2007; Wolyniak, et al., 2009; Wingender y Flemming, 2011; DiCesare, et al., 2012; DiCesare, et al., 2012).

En nuestra región del continente, en particular en países como Argentina y Brasil, se viene evaluando la prevalencia y distribución ambiental de este microorganismo. En este sentido, en Argentina Saramago y colaboradores (Saramago, et al., 2016), al evaluar la materia fecal de 132 pacientes HIV positivos de la región de Buenos Aires observaron una prevalencia de las parasitosis por Cryptosporidium sp. del 11,4\%. Entre los subtipos identificados por estos autores se encuentran el IbA10G2, IaA10G1R4, IaA11G1R4 y IeA11G3T3, en uno de los casos estudiados se identificó una co-infección por las familias Ia y IIa.

Respecto a la prevalencia veterinaria de este parásito, Tiranti y colaboradores (Tiranti, et al., 2011) analizaron la materia fecal de 620 terneros distribuidos en 43 tambos y lo encontraron presente en 19,35\% de los casos, en su mayoría asociados a áreas de suelos con poco drenaje. Resultados similares fueron reportados por Del Coco y colaboradores (Del Coco, et al., 2008), quienes analizando la materia fecal de 280 terneros menores a 30 días de edad determinaron una prevalencia de Cryptosporidium sp. del 17\%. Esta prevalencia trepó al 35\% cuando se consideró a los terneros con diarrea. Más recientemente, Del Coco et al. (2014) evaluaron las familias/subtipos de 75 secuencias del gen gp60 amplificadas a partir de la materia fecal de 73 terneros ubicados en tambos de la provincia de Buenos Aires y en los que se había detectado la presencia de Cryptosporidium sp.. Estos autores identificaron 7 subtipos del protozoario, todos pertenecientes a la familia IIa, y observaron al mismo tiempo una fuerte asociación entre estos y la distribución geográfica de los casos correspondientes. Estudios de este tipo fueron también publicados por Tomazic et al. (2013) a partir del análisis de la materia fecal de 45 terneros distribuidos en nueve granjas de la provincia de Buenos Aires, seis de la provincia de Santa Fe y tres de la provincia de Córdoba. Estos autores observaron la predominancia de los subtipos IIaA17G1R1 y IIaA21G1R1 en Buenos Aires, del subtipo IIaA23G1R1 en Santa Fe y de los subtipos IIaA20G1R1 y IIaA21G1R1 en Córdoba.

Al mismo tiempo, en Brasil, Saramago et al. (2016) evaluando la materia fecal de 89 pacientes HIV positivos de la región de Rio de Janeiro observaron una prevalencia de las parasitosis por Cryptosporidium sp. del 19,1\%.
Respecto a la prevalencia veterinaria de este parásito, Araújo-Junior et al. (2013) analizaron la materia fecal de 100 terneros distribuidos en 10 tambos y encontraron este microorganismo presente en el $26 \%$ de los casos. Análisis de PCR-RFLP identificaron a las especies Cryptosporidium andersonii, Cryptosporidium bovis y Cryptosporidium parvum, en este último caso perteneciente al subtipo IIaA15G2R1, según el análisis de la secuencia de $g p 60$ correspondiente. Más recientemente, Carvalho et al. (2014) evaluaron la prevalencia y subtipos de Cryptosporidium sp. presentes en la materia fecal de 143 terneros distribuidos en tres tambos del estado de Rio de Janeiro. La prevalencia observada del protozoario fue del $16 \%$, mientras que se identificaron ocho subtipos pertenecientes a la familia IIa, cuatro de los cuales fueron descritos por primera vez en la literatura. Respecto a la distribución ambiental de este protozoario, Araújo et al. (2011) encontraron la presencia de Cryptosporidium hominis, Cryptosporidium meleagridis y Cryptosporidium sp. en el 30\% de muestras de aguas ambientales tomadas entre mayo de 2015 y diciembre de 2006 en cuerpos de agua ambiental de la zona del estado de San Pablo. Más recientemente, Campos Almeida et al. (2015) detectaron la presencia de Cryptosporidium sp. en el 8,33\% de las muestras tomadas quincenalmente entre setiembre de 2012 y 2013 en fuentes de agua potable de la región de Londrina. Trabajos de este tipo en otras regiones del mundo muestran que la familia Ib predomina en Europa, América del Norte y Oceanía; el subtipo IbA10G2 es, por ejemplo, prevalente en el norte europeo. La familia Id, descrita en este trabajo, se ha reportado como la segunda de mayor prevalencia en Australia (Chalmers, et al., 2008; O’Brien, et al., 2008; Wielinga, et al., 2008; Xiao, 2010; Zhao, et al., 2016).

Las herramientas presentadas anteriormente e implementadas en este trabajo también tienen el potencial de ser empleadas en estudios para la identificación del origen de contaminación de aguas ambientales por este protozoario (Ruecker, et al., 2012; Wilkes, et al., 2013; Mahmoudi, et al., 2015; DeSilva, et al., 2016; Thivierge, et al., 2016).

En Uruguay la criptosporidiosis fue reportada por primera vez en 1987 por Zanetta et al. (1987). En 2001 Cryptosporidium sp. se identificó en el 7,5\% de niños con diarreas persistentes admitidos en el Hospital Pereira Rossell de Montevideo (Torres, et al., 2001). En 2014 Gonzalez et al. (2014) reportaron que en pacientes con VIH/SIDA del 


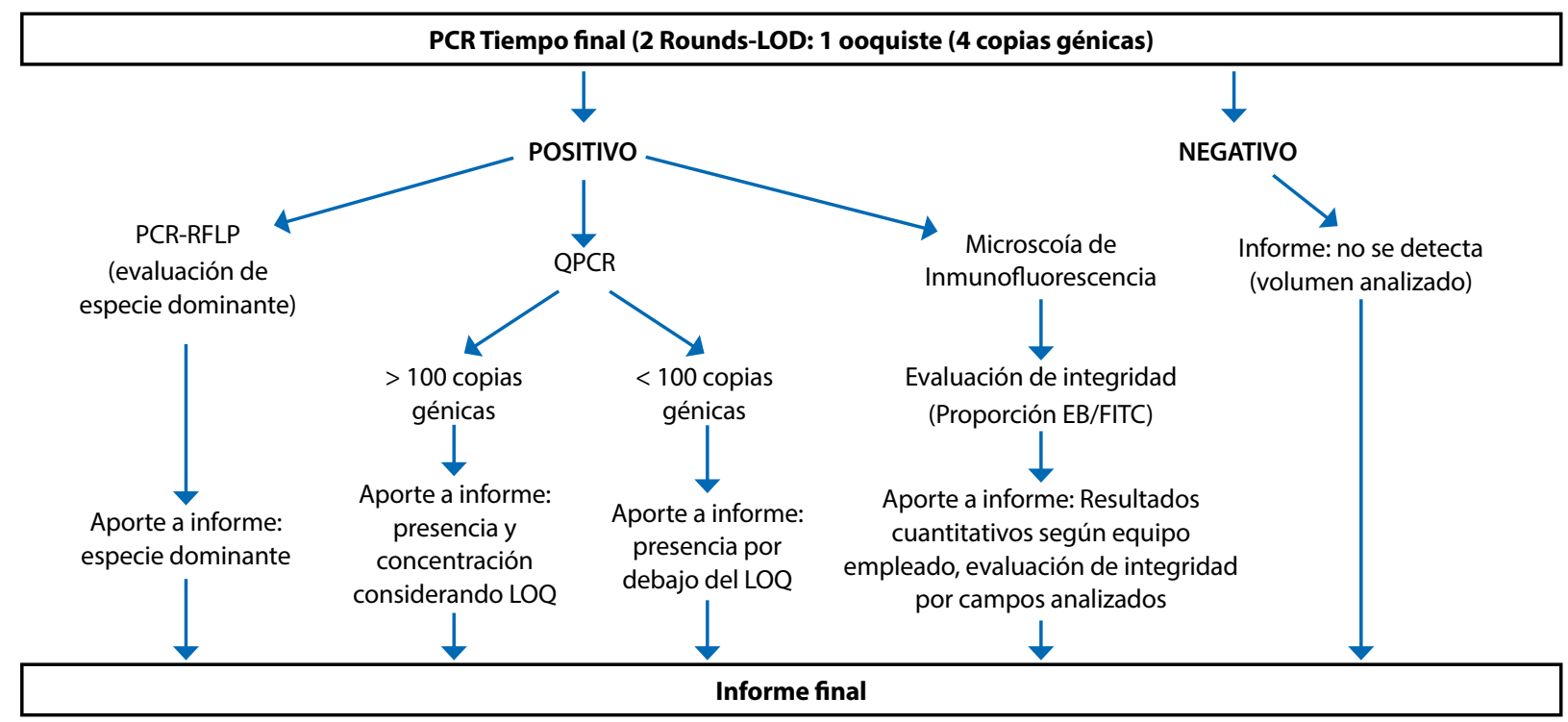

Figura 10. Diagrama de flujo propuesto para laboratorios clínicos o ambientales para determinación de la presencia, concentración, especie e integridad de ooquistes de Cryptosporidium sp. No se incluye en la figura pero queda a consideración de los laboratorios clínicos o ambientales la inclusión de sistemas para la determinación de familias y subtipos de Cryptosporidium sp. LOD: Limit of Detection, LOQ: Limit of Quantification, EB: Evan's Blue, FITC: Fluorescein-isothiocianato.

Servicio de Enfermedades Infecto-Contagiosas (SEIC) de la Administración de los Servicios de Salud del Estado (ASSE) de Uruguay, Cryptosporidium sp. se encontró presente como uno de los agentes causantes de diarrea identificados.

Uruguay cuenta hasta el momento con muy escasa información sobre la prevalencia clínica de esta parasitosis y carece de datos respecto a la distribución geográfica de Cryptosporidium sp.. Dada la significación sanitaria y ambiental de este microorganismo y para contribuir al estudio de estos aspectos se han implementado metodologías moleculares robustas y específicas aplicables por laboratorios clínicos o ambientales uruguayos para la detección, cuantificación, identificación de especies dominantes y evaluación del grado de integridad de ooquistes de Cryptosporidium sp. potencialmente presentes en muestras de aguas ambientales de Uruguay. En este sentido, las herramientas de PCR, PCR-RFLP, QPCR y microscopía de fluorescencia implementadas contribuirán a una mejor evaluación del riesgo representado por la presencia en aguas de este parásito. Asimismo, se han implementado herramientas basadas en el análisis de polimorfismos de la secuencia nucleotídica de la región 3' del gen gp60 de Cryptosporidium $s p$. que permiten la determinación de familias y subtipos moleculares de este protozoario. Tal como se describió anteriormente dicha estrategia es ampliamente empleada en el estudio de la epidemiología de esta parasitosis así como en la determinación del origen, fuentes y potencial de dispersión ambiental de este protozoario (Feltus, et al., 2006; Trotz-Williams, et al., 2006; Jex, et al., 2007; Thompson, et al., 2007; Xiao, et al., 2007; Jex, et al., 2008; Santin, et al., 2008; Zintl, et al., 2009; Baldursson y Karanis, 2011; Hlavsa, et al., 2011; Chalmers, 2012). Durante el proceso de implementación de estas metodologías se ha identificado la presencia de Cryptosporidium parvum en aguas ambientales de Uruguay y de Cryptosporidium hominis en dos casos clínicos humanos de criptosporidiosis, identificando la presencia en ambos del subtipo IdA19T4. La significación de este hallazgo y prevalencia de este subtipo debe ser estudiada en profundidad (Cama, et al., 2007; Chalmers, et al., 2008; Wielinga, et al., 2008; Feng, et al., 2009; Ng, et al., 2010; Xiao, 2010).

Dado que esta capacidad de identificar subtipos no es única para $g p 60$, se espera implementar en el futuro estrategias basadas en el análisis de las secuencias de otros genes polimórficos y estrategias de Multi-Locus Sequence Typing (MLST) (Wielinga, et al., 2008; Feng, et al., 2014) que permitan complementar y profundizar estudios epidemiológicos de esta parasitosis en Uruguay. En conclusión, considerando el tipo de información aportada por cada una de las herramientas implementadas así como el desempeño de los sistemas de PCR, se propone para el control y seguimiento clínico y ambiental de este protozoario un algoritmo de trabajo que como primera etapa evalúe la presencia de Cryptosporidium sp. por el sistema implementado de PCR de tiempo final. En caso de registrarse resultados positivos, se deberían disparar ensayos paralelos de PCR-RFLP, PCR de tiempo real y de microscopía de fluorescencia (Figura 10). Estudios clínicos epidemiológicos o de determinación del origen de potenciales eventos de contaminación ambiental deberían apoyarse en la determinación de familias y subtipos moleculares dominantes de este protozoario.

\section{Reconocimientos}

Los autores agradecen a la MSc. Lucía Boccardi, Dra. Ana Maquieira, MSc. Paula Mussio, Ing. Saúl Garat e Ing. Alejandro Iriburo el aporte y apoyo a este trabajo. El mismo se enmarca en el Convenio de Colaboración entre OSE y LATU aprobado por ose según RD N 1218/15. 


\section{Referencias}

Alves, M., Xiao, L., Sulaiman, I., Lal, A. A., Matos, O. y Antunes, F., 2003. Subgenotype analysis of cryptosporidium isolates from humans, cattle, and zoo ruminants in Portugal. En: J Clin Microbiol, 41(6), pp.2744-2747.

Angles, M. L., J. P. Chandy, P. T. Cox, I. H. Fisher y M. R. Warnecke, 2007. Implications of biofilm-associated waterborne Cryptosporidium oocysts for the water industry. En: Trends Parasitol, 23(8), pp.352-356.

Araújo-Junior, F. M. P. y. S. R. S. L. J. P., 2013. Identifcation of Cryptosporidium species and genotypes in dairy cattle in Brazil. En: Rev. Bras. Parasitol. Vet., Jaboticabal, 22(1), pp.22-28.

Araujo, R. S., M. Dropa, L. N. Fernandes, T. T. Carvalho, M. I. Sato, R. M. Soares, G. R. Matte y M. H. Matte, 2011. Genotypic characterization of Cryptosporidium hominis from water samples in Sao Paulo, Brazil. En: Am J Trop Med Hyg, 85(5), pp.834-838.

Baldursson, S. y Karanis, P., 2011. Waterborne transmission of protozoan parasites: review of worldwide outbreaks - an update 2004-2010. En: Water Res., 45(20), pp.6603-6614.

Bouzid, M., Hunter, P. R., Chalmers, R. M. y Tyler, K. M., 2013. Cryptosporidium pathogenicity and virulence. En: Clin Microbiol Rev, 26(1), pp.115-134.

Caccio, S. M., Sannella, A. R., Mariano, V., Valentini, S., Berti, F., Tosini, F. y Pozio, E., 2013. A rare Cryptosporidium parvum genotype associated with infection of lambs and zoonotic transmission in Italy. En: Vet Parasitol, 191(1-2), pp.128-131.

Cama, V. A., Ross, J. M., Crawford, S., Kawai, V., ChavezValdez, R., Vargas, D., Vivar, A., Ticona, E., Navincopa, M., Williamson, J., Ortega, Y., Gilman, R.H., Bern, C. y Xiao, L., 2007. Differences in clinical manifestations among Cryptosporidium species and subtypes in HIV-infected persons. En: J Infect Dis, 196(5), pp.684-691.

Campos Almeida, Jonatas; Cardoso Martins, Felippe Danyel; Ferreira Neto, José Maurício, Moreira dos Santos, Maíra, Garcia, João Luis y Teodorico Navarro, Italmar, Kiyomi Kuroda, Emília, Lemos Freire, Roberta, 2015. Occurrence of Cryptosporidium spp. and Giardia spp. in a public water-treatment system, Paraná, Southern Brazil. En: Braz. J. Vet. Parasitol., Jaboticabal, 24(3), pp.303-308.

Castro-Hermida, J. A., Garcia-Presedo, I., Almeida, A., Gonzalez-Warleta, M., Correia Da Costa, J.M. y Mezo, M., 2008. Presence of Cryptosporidium spp. and Giardia duodenalis through drinking water. En: Sci Total Environ, 405(1-3), pp.45-53.

Chalmers, R. M., 2008. Cryptosporidium: from laboratory diagnosis to surveillance and outbreaks. En: Parasite, 15(3), pp.372-378.

Chalmers, R. M., 2012. Waterborne outbreaks of cryptosporidiosis. En: Ann Ist Super Sanita, 48(4), pp.429-446.

Chalmers, R. M., Hadfield, S. J., Jackson, C. J., Elwin, K., Xiao, L. y Hunter, P., 2008. Geographic linkage and variation in Cryptosporidium hominis. En: Emerg Infect Dis, 14(3), pp.496-498.

Chalmers, R. M., R. Smith, K. Elwin, F. A. Clifton-Hadley y M. Giles, 2011. Epidemiology of anthroponotic and zoonotic human cryptosporidiosis in England and Wales, 20042006. En: Epidemiol Infect, 139(5), pp.700-712.
Chalmers, R. M., A. L. Thomas, B. A. Butler y M. C. Morel, 2005. Identification of Cryptosporidium parvum genotype 2 in domestic horses. En: Vet Rec, 156(2), pp.49-50.

Chappell, C. L., P. C. Okhuysen, C. R. Sterling y H. L. DuPont, 1996. Cryptosporidium parvum: intensity of infection and oocyst excretion patterns in healthy volunteers. En: J Infect Dis, 173(1), pp.232-236.

Cohen, S., F. Dalle, A. Gallay, M. Di Palma, A. Bonnin y H. D. Ward, 2006. Identification of Cpgp40/15 Type Ib as the predominant allele in isolates of Cryptosporidium spp. from a waterborne outbreak of gastroenteritis in South Burgundy, France. En: J Clin Microbiol, 44(2), pp.589-591.

Current, W. L. y L. S. Garcia, 1991. Cryptosporidiosis. En: Clin Microbiol Rev, 4(3), pp. 325-358.

Del Coco, V. F., M. A. Cordoba y Basualdo, J. A., 2008. Cryptosporidium infection in calves from a rural area of Buenos Aires, Argentina. En: Vet Parasitol, 158(1-2), pp:31-35.

Del Coco, V. F., M. A. Cordoba, G. Bilbao, A. P. de Almeida Castro, J. A. Basualdo, R. Fayer y Santin, M., 2014. Cryptosporidium parvum GP60 subtypes in dairy cattle from Buenos Aires, Argentina. En: Res Vet Sci, 96(2), pp.311-314.

DeSilva, M. B., S. Schafer, M. Kendall Scott, B. Robinson, A. Hills, G. L. Buser, K. Salis, J. Gargano, J. Yoder, V. Hill, L. Xiao, D. Roellig y K. Hedberg, 2016. Communitywide cryptosporidiosis outbreak associated with a surface water-supplied municipal water system--Baker City, Oregon, 2013. En: Epidemiol Infect, 144(2), pp.274-284.

DiCesare, E. A., B. R. Hargreaves y K. L. Jellison, 2012. Biofilm roughness determines Cryptosporidium parvum retention in environmental biofilms. En: Appl Environ Microbiol, 78(12), pp.4187-4193.

DiCesare, E. A., B. R. Hargreaves and K. L. Jellison, 2012. Biofilms reduce solar disinfection of Cryptosporidium parvum oocysts. En: Appl Environ Microbiol, 78(12), pp.4522-4525.

DiGiorgio, C. L., D. A. Gonzalez y C. C. Huitt, 2002. Cryptosporidium and Giardia recoveries in natural waters by using environmental protection agency method 1623 . En: Appl Environ Microbiol, 68(12), pp.5952-5955.

DuPont, H. L., C. L. Chappell, C. R. Sterling, P. C. Okhuysen, J. B. Rose y W. Jakubowski, 1995. The infectivity of Cryptosporidium parvum in healthy volunteers. En: $N$ Engl J Med, 332(13), pp.855-859.

Dyachenko, V., Y. Kuhnert, R. Schmaeschke, M. Etzold, N. Pantchev y A. Daugschies, 2010. Occurrence and molecular characterization of Cryptosporidium spp. genotypes in European hedgehogs (Erinaceus europaeus L.) in Germany. En: Parasitology, 137(2), pp.205-216.

Ethelberg, S., M. Lisby, L. S. Vestergaard, H. L. Enemark, K. E. Olsen, C. R. Stensvold, H. V. Nielsen, L. J. Porsbo, A. M. Plesner y K. Molbak, 2009. A foodborne outbreak of Cryptosporidium hominis infection. En: Epidemiol Infect, 137(3), pp.348-356.

Fayer, R., 2010. Taxonomy and species delimitation in Cryptosporidium. En: Exp Parasitol, 124(1), pp.90-97.

Feltus, D. C., C. W. Giddings, B. L. Schneck, T. Monson, D. Warshauer y J. M. McEvoy, 2006. Evidence supporting zoonotic transmission of Cryptosporidium spp. in Wisconsin. En: J Clin Microbiol, 44(12), pp.4303-4308.

Feng, Y., N. Li, L. Duan y L. Xiao, 2009. Cryptosporidium genotype and subtype distribution in raw wastewater 
in Shanghai, China: evidence for possible unique Cryptosporidium hominis transmission. En: J Clin Microbiol, 47(1), pp.153-157.

Feng, Y., N. Tiao, N. Li, M. Hlavsa y L. Xiao, 2014. Multilocus sequence typing of an emerging Cryptosporidium hominis subtype in the United States. En: J Clin Microbiol, 52(2), pp.524-530.

Ferguson, C., C. Kaucner, M. Krogh, D. Deere y M. Warnecke, 2004. Comparison of methods for the concentration of Cryptosporidium oocysts and Giardia cysts from raw waters. En: Can J Microbiol, 50(9), pp.675-682.

Gatei, W., C. A. Hart, R. H. Gilman, P. Das, V. Cama y L. Xiao, 2006. Development of a multilocus sequence typing tool for Cryptosporidium hominis. En: J Eukaryot Microbiol, 53 Suppl 1, pp.S43-48.

Geurden, T., E. Goossens, B. Levecke, F. Vercammen, J. Vercruysse y E. Claerebout, 2009. Occurrence and molecular characterization of Cryptosporidium and Giardia in captive wild ruminants in Belgium. En: J Zoo Wildl Med, 40(1), pp.126-130.

Goh, S., M. Reacher, D. P. Casemore, N. Q. Verlander, R. Chalmers, M. Knowles, J. Williams, K. Osborn y S. Richards, 2004. Sporadic cryptosporidiosis, North Cumbria, England, 1996-2000. En: Emerg Infect Dis, 10(6), pp.1007-1015.

González, T.; Cabrera, F.; Rodriguez, T.; Combol, A.; Acuña, A., 2014. Enteroparasitosis en pacientes VIH/SIDA del Servicio de Enfermedades Infecto-Contagiosas (SEIC), ASSE. En: Rev Urug Patol Clin, 53(76).

Gormley, F. J., C. L. Little, R. M. Chalmers, N. Rawal y G. K. Adak, 2011. Zoonotic cryptosporidiosis from petting farms, England and Wales, 1992-2009. En: Emerg Infect Dis, 17(1), pp.151-152.

Harper, C. M., N. A. Cowell, B. C. Adams, A. J. Langley y T. D. Wohlsen, 2002. Outbreak of Cryptosporidium linked to drinking unpasteurised milk. En: Commun Dis Intell $Q$ Rep, 26(3), pp.449-450.

Harrison, S. L., R. Nelder, L. Hayek, I. F. Mackenzie, D. P. Casemore y D. Dance, 2002. Managing a large outbreak of cryptosporidiosis: how to investigate and when to decide to lift a 'boil water' notice. En: Commun Dis Public Health, 5(3), pp.230-239.

Hlavsa, M. C., V. A. Roberts, A. R. Anderson, V. R. Hill, A. M. Kahler, M. Orr, L. E. Garrison, L. A. Hicks, A. Newton, E. D. Hilborn, T. J. Wade, M. J. Beach, J. S. Yoder y Cdc, 2011. Surveillance for waterborne disease outbreaks and other health events associated with recreational water --- United States, 2007--2008. En: mMWR Surveill Summ, 60(12), pp.1-32.

Howe, A. D., S. Forster, S. Morton, R. Marshall, K. S. Osborn, P. Wright y P. R. Hunter, 2002. Cryptosporidium oocysts in a water supply associated with a cryptosporidiosis outbreak. En: Emerg Infect Dis, 8(6), pp.619-624.

Hunter, P. R., S. Hughes, S. Woodhouse, N. Raj, Q. Syed, R. M. Chalmers, N. Q. Verlander y J. Goodacre, 2004. Health sequelae of human cryptosporidiosis in immunocompetent patients. En: Clin Infect Dis, 39(4), pp.504-510.

Hunter, P. R., D. C. Wilkinson, I. R. Lake, F. C. Harrison, Q. Syed, S. J. Hadfield y R. M. Chalmers, 2008. Microsatellite typing of Cryptosporidium parvum in isolates from a waterborne outbreak. En: J Clin Microbiol, 46(11), pp.3866-3867.
Ives, R. L., A. M. Kamarainen, D. E. John y J. B. Rose, 2007. Use of cell culture to assess Cryptosporidium parvum survival rates in natural groundwaters and surface waters. En: Appl Environ Microbiol, 73(18), pp.5968-5970.

Jex, A. R., A. Pangasa, B. E. Campbell, M. Whipp, G. Hogg, M. I. Sinclair, M. Stevens y R. B. Gasser, 2008. Classification of Cryptosporidium species from patients with sporadic cryptosporidiosis by use of sequence-based multilocus analysis following mutation scanning. En: J Clin Microbiol, 46(7), pp.2252-2262.

Jex, A. R., U. M. Ryan, J. Ng, B. E. Campbell, L. Xiao, M. Stevens y R. B. Gasser, 2007. Specific and genotypic identification of Cryptosporidium from a broad range of host species by nonisotopic SSCP analysis of nuclear ribosomal DNA. En: Electrophoresis, 28(16), pp.2818-2825.

Johnson, C. R., S. K. Gorla, M. Kavitha, M. Zhang, X. Liu, B. Striepen, J. R. Mead, G. D. Cuny y L. Hedstrom, 2013. Phthalazinone inhibitors of inosine-5'-monophosphate dehydrogenase from Cryptosporidium parvum. En: Bioorg Med Chem Lett, 23(4), pp. 1004-1007.

Koehler, A. V., R. S. Bradbury, M. A. Stevens, S. R. Haydon, A. R. Jex y R. B. Gasser, 2013. Genetic characterization of selected parasites from people with histories of gastrointestinal disorders using a mutation scanningcoupled approach. En: Electrophoresis, 34(12), pp.17201728.

Lake, I. R., F. C. Harrison, R. M. Chalmers, G. Bentham, G. Nichols, P. R. Hunter, R. S. Kovats y C. Grundy, 2007. Case-control study of environmental and social factors influencing cryptosporidiosis. En: Eur J Epidemiol, 22(11), pp.805-811.

Lee, Y., L. L. Gomez, I. T. McAuliffe y V. C. Tsang, 2004. Evaluation of Cryptosporidium parvum oocyst recovery efficiencies from various filtration cartridges by electrochemiluminescence assays. En: Lett Appl Microbiol, 39(2), pp.156-162.

Leoni, F., H. Gomez-Couso, M. E. Ares-Mazas y J. McLauchlin, 2007. Multilocus genetic analysis of Cryptosporidium in naturally contaminated bivalve molluscs. En: J Appl Microbiol, 103(6), pp.2430-2437.

Leoni, F., M. E. Mallon, H. V. Smith, A. Tait y J. McLauchlin, 2007. Multilocus analysis of Cryptosporidium hominis and Cryptosporidium parvum isolates from sporadic and outbreak-related human cases and C. parvum isolates from sporadic livestock cases in the United Kingdom. En: $J$ Clin Microbiol, 45(10), pp.3286-3294.

Levine, N. D., 1984. Taxonomy and review of the coccidian genus Cryptosporidium (protozoa, apicomplexa). En: $J$ Protozool, 31(1), pp.94-98.

Mac Kenzie, W. R., N. J. Hoxie, M. E. Proctor, M. S. Gradus, K. A. Blair, D. E. Peterson, J. J. Kazmierczak, D. G. Addiss, K. R. Fox, J. B. Rose, et al., 1994. A massive outbreak in Milwaukee of Cryptosporidium infection transmitted through the public water supply. En: N Engl J Med, 331(3), pp.161-167.

Mahmoudi, M. R., E. Nazemalhosseini-Mojarad, B. Kazemi, A. Haghighi, A. Mirzaei, A. Mohammadiha, S. Jahantab, L. Xiao and P. Karanis, 2015. Cryptosporidium genotypes and subtypes distribution in river water in Iran. En: $J$ Water Health, 13(2), pp.600-606.

Manser, M., M. Granlund, H. Edwards, A. Saez, E. Petersen, B. Evengard, P. Chiodini, M. European Society of Clinical y P. Infectious Diseases Study Group on Clinical, 2014 
Detection of Cryptosporidium and Giardia in clinical laboratories in Europe--a comparative study. En: Clin Microbiol Infect, 20(1), pp.O65-71.

Carvalho Machado do Couto, Melissa, M. d. F. L. y T. C. B. d. Bomfim, 2014. New Cryptosporidium parvum subtypes of IIa subfamily in dairy calves from Brazil. En: Acta Tropica, (130),pp.117-122.

Miller, R. A., M. A. Bronsdon y W. R. Morton, 1990. Experimental cryptosporidiosis in a primate model. En: $J$ Infect Dis, 161(2), pp.312-315.

Mons, C., A. Dumetre, S. Gosselin, C. Galliot y L. Moulin, 2009. Monitoring of Cryptosporidium and Giardia river contamination in Paris area. En: Water Res, 43(1), pp.211-217.

Ng, J., B. MacKenzie y U. Ryan, 2010. Longitudinal multi-locus molecular characterisation of sporadic Australian human clinical cases of cryptosporidiosis from 2005 to 2008. En: Exp Parasitol, 125(4), pp.348-356.

Ng, J., R. Yang, V. Whiffin, P. Cox y U. Ryan, 2011. Identification of zoonotic Cryptosporidium and Giardia genotypes infecting animals in Sydney's water catchments. En: Exp Parasitol, 128(2), pp.138-144.

Ng, J. S., N. Pingault, R. Gibbs, A. Koehler y U. Ryan, 2010. Molecular characterisation of Cryptosporidium outbreaks in Western and South Australia. En: Exp Parasitol, 125(4), pp.325-328.

O'Brien, E., L. McInnes y U. Ryan, 2008. Cryptosporidium GP60 genotypes from humans and domesticated animals in Australia, North America and Europe. En: Exp Parasitol, 118(1), pp.118-121.

O'Connor, R. M., J. W. Wanyiri, A. M. Cevallos, J. W. Priest y H. D. Ward, 2007. Cryptosporidium parvum glycoprotein gp40 localizes to the sporozoite surface by association with gp15. En: Mol Biochem Parasitol, 156(1), pp.80-83.

O’Donoghue, P. J., 1995. Cryptosporidium and cryptosporidiosis in man and animals. En: Int J Parasitol, 25(2), pp.139-195.

O'Handley, R. M. y M. E. Olson, 2006. Giardiasis and cryptosporidiosis in ruminants. En: Vet Clin North Am Food Anim Pract, 22(3), pp.623-643.

Peng, M. M., O. Matos, W. Gatei, P. Das, M. Stantic-Pavlinic, C. Bern, I. M. Sulaiman, S. Glaberman, A. A. Lal y L. Xiao, 2001. A comparison of Cryptosporidium subgenotypes from several geographic regions. En: J Eukaryot Microbiol, Suppl, pp.28S-31S.

Petry, F., 2004. Structural analysis of Cryptosporidium parvum. En: Microsc Microanal, 10(5), pp.586-601.

Plutzer, J. y P. Karanis, 2009. Genetic polymorphism in Cryptosporidium species: an update. En: Vet Parasitol, 165(3-4), pp.187-199.

Putignani, L. y D. Menichella, 2010. Global distribution, public health and clinical impact of the protozoan pathogen cryptosporidium. En: Interdiscip Perspect Infect Dis, 2010, pii.753512.

Saramago Peralta, Regina Helena, J. N. V., Flavia de Souza Cunha, F. C. S. María Laura Pantano, Sidnei da Silva y J. M. P. Osvaldo Germán Astudillo, Silvana Carnevale, 2016. Genetic diversity of Cryptosporidium identified in clinical samples from cities in Brazil and Argentina. En: Mem Inst Oswaldo Cruz, 111(1), pp.30-36.

Robertson, B., M. I. Sinclair, A. B. Forbes, M. Veitch, M. Kirk, D. Cunliffe, J. Willis y C. K. Fairley, 2002. Case-control studies of sporadic cryptosporidiosis in Melbourne and Adelaide, Australia. En: Epidemiol Infect, 128(3), pp.419-431.
Robinson, G. y R. M. Chalmers, 2010. The European rabbit (Oryctolagus cuniculus), a source of zoonotic cryptosporidiosis. En: Zoonoses Public Health, 57(7-8), pp.e1-13.

Roy, S. L., S. M. DeLong, S. A. Stenzel, B. Shiferaw, J. M. Roberts, A. Khalakdina, R. Marcus, S. D. Segler, D. D. Shah, S. Thomas, D. J. Vugia, S. M. Zansky, V. Dietz y M. J. Beach, 2004. Risk factors for sporadic cryptosporidiosis among immunocompetent persons in the United States from 1999 to 2001. En: J Clin Microbiol, 42(7), pp.2944-2951.

Ruecker, N. J., J. C. Matsune, G. Wilkes, D. R. Lapen, E. Topp, T. A. Edge, C. W. Sensen, L. Xiao y N. F. Neumann, 2012. Molecular and phylogenetic approaches for assessing sources of Cryptosporidium contamination in water. En: Water Res, 46(16), pp.5135-5150.

Santin, M., J. M. Trout y R. Fayer, 2008. A longitudinal study of cryptosporidiosis in dairy cattle from birth to 2 years of age. En: Vet Parasitol, 155(1-2), pp.15-23.

Shields, J. M., V. R. Hill, M. J. Arrowood y M. J. Beach, 2008. Inactivation of Cryptosporidium parvum under chlorinated recreational water conditions. En: $J$ Water Health, 6(4), pp.513-520.

Slavin, D., 1955. Cryptosporidium meleagridis (sp. nov.). En: $J$ Comp Pathol, 65(3), pp. 262-266.

Smith, H. V. y R. A. Nichols, 2010. Cryptosporidium: detection in water and food. En: Exp Parasitol, 124(1), pp.61-79.

Snelling, W. J., L. Xiao, G. Ortega-Pierres, C. J. Lowery, J. E. Moore, J. R. Rao, S. Smyth, B. C. Millar, P. J. Rooney, M. Matsuda, F. Kenny, J. Xu y J. S. Dooley, 2007. Cryptosporidiosis in developing countries. En: J Infect Dev Ctries, 1(3), pp.242-256.

Sopwith, W., K. Osborn, R. Chalmers y M. Regan, 2005. The changing epidemiology of cryptosporidiosis in North West England. En: Epidemiol Infect, 133(5), pp.785-793.

Strong, W. B., J. Gut y R. G. Nelson, 2000. Cloning and sequence analysis of a highly polymorphic Cryptosporidium parvum gene encoding a 60-kilodalton glycoprotein and characterization of its 15 - and 45-kilodalton zoite surface antigen products. En: Infect Immun, 68(7), pp.4117-4134.

Sulaiman, I. M., P. R. Hira, L. Zhou, F. M. Al-Ali, F. A. AlShelahi, H. M. Shweiki, J. Iqbal, N. Khalid y L. Xiao, 2005. Unique endemicity of cryptosporidiosis in children in Kuwait. En: J Clin Microbiol, 43(6), pp.2805-2809.

Tanriverdi, S., J. C. Blain, B. Deng, M. T. Ferdig y G. Widmer, 2007. Genetic crosses in the apicomplexan parasite Cryptosporidium parvum define recombination parameters. En: Mol Microbiol, 63(5), pp.1432-1439.

Thivierge, K., A. Iqbal, B. Dixon, R. Dion, B. Levesque, P. Cantin, L. Cedilotte, M. Ndao, J. F. Proulx y C. P. Yansouni, 2016. Cryptosporidium hominis Is a Newly Recognized Pathogen in the Arctic Region of Nunavik, Canada: Molecular Characterization of an Outbreak. En: PLoS Negl Trop Dis, 10(4), p.e0004534.

Thompson, H. P., J. S. Dooley, J. Kenny, M. McCoy, C. J. Lowery, J. E. Moore y L. Xiao, 2007. Genotypes and subtypes of Cryptosporidium spp. in neonatal calves in Northern Ireland. En: Parasitol Res, 100(3), pp.619-624.

Tiranti, K., A. Larriestra, C. Vissio, N. Picco, F. Alustiza, A. Degioanni y A. Vivas, 2011. Prevalence of Cryptosporidium spp. and Giardia spp., spatial clustering 
and patterns of shedding in dairy calves from Cordoba, Argentina. En: Rev Bras Parasitol Vet, 20(2), pp.140-147.

Tomazic, M. L., J. Maidana, M. Dominguez, E. L. Uriarte, R. Galarza, C. Garro, M. Florin-Christensen y L. Schnittger, 2013. Molecular characterization of Cryptosporidium isolates from calves in Argentina. En: Vet Parasitol, 198(34), pp.382-386

Torres, M. E., M. C. Pirez, F. Schelotto, G. Varela, V. Parodi, F. Allende, E. Falconi, L. Dell'Acqua, P. Gaione, M. V. Mendez, A. M. Ferrari, A. Montano, E. Zanetta, A. M. Acuna, H. Chiparelli y E. Ingold, 2001. Etiology of children's diarrhea in Montevideo, Uruguay: associated pathogens and unusual isolates. En: J Clin Microbiol, 39(6), pp.2134-2139.

Trotz-Williams, L. A., D. S. Martin, W. Gatei, V. Cama, A. S. Peregrine, S. W. Martin, D. V. Nydam, F. Jamieson y L. Xiao, 2006. Genotype and subtype analyses of Cryptosporidium isolates from dairy calves and humans in Ontario. En: Parasitol Res, 99(4), pp.346-352.

Tyzzer, E. E., 1910. An extracellular Coccidium, Cryptosporidium muris (Gen. Et Sp. Nov.), of the gastric Glands of the Common Mouse. En: J Med Res, 23(3), pp.487-510 483.

Tzipori, S. y G. Widmer, 2000. The biology of Cryptosporidium. En: Contrib Microbiol, 6, pp.1-32.

UK Environment Agency, 2010. The microbiology of drinking water. Part 14 - Methods for the isolation, identification and enumeration of Cryptosporidium oocysts and Giardia cysts. Rotherham: Environment Agency

Waldron, L. S., B. C. Ferrari, C. Cheung-Kwok-Sang, P. J. Beggs, N. Stephens y M. L. Power, 2011. Molecular epidemiology and spatial distribution of a waterborne cryptosporidiosis outbreak in Australia. En: Appl Environ Microbiol, 77(21), pp.7766-7771.

Widmer, G. y Y. Lee, 2010. Comparison of single- and multilocus genetic diversity in the protozoan parasites Cryptosporidium parvum y C. hominis. En: Appl Environ Microbiol, 76(19), pp.6639-6644.

Wielinga, P. R., A. de Vries, T. H. van der Goot, T. Mank, M. H. Mars, L. M. Kortbeek y J. W. van der Giessen, 2008. Molecular epidemiology of Cryptosporidium in humans and cattle in The Netherlands. En: Int J Parasitol, 38(7), pp.809-817.

Wilkes, G., N. J. Ruecker, N. F. Neumann, V. P. Gannon, C. Jokinen, M. Sunohara, E. Topp, K. D. Pintar, T. A. Edge y D. R. Lapen, 2013. Spatiotemporal analysis of Cryptosporidium species/genotypes and relationships with other zoonotic pathogens in surface water from mixed-use watersheds. En: Appl Environ Microbiol, 79(2), pp.434-448.

Wingender, J. and H. C. Flemming, 2011. Biofilms in drinking water and their role as reservoir for pathogens. En: Int J Hyg Environ Health, 214(6), pp.417-423.
Wohlsen, T., J. Bates, B. Gray y M. Katouli, 2004. Evaluation of five membrane filtration methods for recovery of Cryptosporidium and Giardia isolates from water samples. En: Appl Environ Microbiol, 70(4), pp.2318-2322.

Wolyniak, E. A., B. R. Hargreaves y K. L. Jellison, 2009. Retention and release of Cryptosporidium parvum oocysts by experimental biofilms composed of a natural stream microbial community. En: Appl Environ Microbiol, 75(13), pp.4624-4626.

Xiao, L., 2010. Molecular epidemiology of cryptosporidiosis: an update. En: Exp Parasitol, 124(1), pp.80-89.

Xiao, L., K. Alderisio, J. Limor, M. Royer y A. A. Lal, 2000. Identification of species and sources of Cryptosporidium oocysts in storm waters with a small-subunit rRNAbased diagnostic and genotyping tool. En: Appl Environ Microbiol, 66(12), pp.5492-5498.

Xiao, L., M. C. Hlavsa, J. Yoder, C. Ewers, T. Dearen, W. Yang, R. Nett, S. Harris, S. M. Brend, M. Harris, L. Onischuk, A. L. Valderrama, S. Cosgrove, K. Xavier, N. Hall, S. Romero, S. Young, S. P. Johnston, M. Arrowood, S. Roy y M. J. Beach, 2009. Subtype analysis of Cryptosporidium specimens from sporadic cases in Colorado, Idaho, New Mexico, and Iowa in 2007: widespread occurrence of one Cryptosporidium hominis subtype and case history of an infection with the Cryptosporidium horse genotype. En: $J$ Clin Microbiol, 47(9), pp.3017-3020.

Xiao, L., J. Limor, U. M. Morgan, I. M. Sulaiman, R. C. Thompson y A. A. Lal, 2000. Sequence differences in the diagnostic target region of the oocyst wall protein gene of Cryptosporidium parasites. En: Appl Environ Microbiol, 66(12), pp.5499-5502.

Xiao, L., L. Zhou, M. Santin, W. Yang y R. Fayer, 2007. Distribution of Cryptosporidium parvum subtypes in calves in eastern United States. En: Parasitol Res, 100(4), pp.701-706.

Yu, J. R., S. U. Lee y W. Y. Park, 2009. Comparative sensitivity of PCR primer sets for detection of Cryptosporidium parvum. En: Korean J Parasitol, 47(3), pp.293-297.

Zanetta, E., 1987. Primeros hallazgos en Uruguay de un nuevo agente de diarrea aguda infantil: Cryptosporidium sp. En: Arch Ped Uruguay, 58(1), pp.37-45.

Zhao, G. H., Y. Q. Fang, U. Ryan, Y. X. Guo, F. Wu, S. Z. Du, D. K. Chen y Q. Lin, 2016. Dynamics of Th17 associating cytokines in Cryptosporidium parvum-infected mice. En: Parasitol Res, 115(2), pp.879-887.

Zintl, A., A. F. Proctor, C. Read, T. Dewaal, N. Shanaghy, S. Fanning y G. Mulcahy 2009. The prevalence of Cryptosporidium species and subtypes in human faecal samples in Ireland. En: Epidemiol Infect, 137(2), pp.270-277. 